\title{
Endocarditis trombótica no bacteriana y neoplasia pulmonar
}

\author{
I. DE LA IGLESIA FANJUL, D. ALONSO RODRÍGUEZ \\ Servicios de Medicina Interna y ${ }^{1}$ Cardiología. Hospital de León
}

NON-BACTERIAL THROMBOTIC ENDOCARDITIS AND LUNG NEO-
PLASM

\section{RESUMEN}

Se presenta el caso de una paciente diagnosticada de endocarditis trombótica no bacteriana asociada a adenocarcinoma pulmonar que debuta como ictus embólico de repetición, demostrándose vegetaciones en válvula mitral en ausencia de cuadro infeccioso agudo

El caso es relevante por ser la habitual presentación de la endocarditis trombótica no bacteriana y por la importancia de un diagnóstico clínico precoz

PALABRAS CLAVE: Ictus. Neoplasia. Endocarditis. Ecocardiograma.

\begin{abstract}
A woman with the final diagnosis of non-bacterial thrombotic endocarditis associated to pulmonary adenocarcinoma is reported. She had had repetitive embolic strokes as the first manifestation, with vegetations on the mitral valve and without signs of acute infectious disease.

The case is interesting because is an usually case of nonbacterial thrombotic endocarditis and the importance of an early diagnostic
\end{abstract}

KEY WORDS: Stroke. Neoplasm. Endocarditis. Echocardiogram.

De la Iglesia Fanjul I, Alonso Rodríguez D. Endocarditis trombótica no bacteriana y neoplasia pulmonar. An Med Interna (Madrid) 2006; 23: 487-489.

\section{INTRODUCCIÓN}

Esta entidad es descrita por primera vez por Ziegler en 1988, con el término de tromboendocarditis $(1,2)$ recibiendo en 1936 el término de endocarditis trombótica no bacteriana (ETNB) por Gross y Friedberg $(2,3)$.

Se trata de una patología relativamente frecuente, aunque infradiagnosticada, ya que vegetaciones causadas por ETNB aparecen en el 1,2\% de las autopsias; con variación según las series: desde el 0,3\% hasta el 9,3\% $(2,4,6)$.

Presentamos el caso de una paciente con infartos isquémicos cerebrales múltiples que fue diagnosticada de ETNB en el contexto de un adenocarcinoma pulmonar.

\section{CASO APORTADO}

Mujer de 51 años sin antecedentes de interés que ingresa por ictus con disnomia y paresia derecha, demostrándose por scanner y resonancia magnética múltiples focos isquémicos, que sugieren origen embólico.
Al ingreso estaba afebril, con tensión arterial 120/60 mmHg,destacaba en la exploración neurológica, fluencia verbal reducida con parafasias frecuentes, facial central derecho, un déficit motor braquio-crural derecho y una respuesta plantar derecha indiferente. La exploración sistémica era normal salvo petequias en región tibial de extremidad inferior derecha y hemorragias en astilla en varios dedos de ambas manos.

La analítica era normal salvo un aumento de los reactantes de fase aguda. El electrocardiograma, doppler transcraneal, doppler continuo carotídeo y fondo de ojo eran normales. La ecografía cardiaca, transtorácica y transesofágica, mostraba un foramen ovale permeable, prolapso mitral y una verruga de 15 milimetros sobre el velo posterior de la mitral con una insuficiencia mitral (IM) ligera. Con la sospecha de endocarditis bacteriana subaguda se inició tratamiento antibiótico empírico con Vancomicina y Gentamicina previa extracción de hemocultivos estando la paciente afebril, situación en la que se mantuvo durante el ingreso.

En la radiografia de tórax se observaba un nódulo en lóbulo inferior izquierdo (LII) que posteriormente se confirma en scanner como una masa de 3,5 centimetros en LII, nódulos satélites, adenopatías contralaterales y linfangitis carcinomatosa sugerentes de proceso neoplásico. 


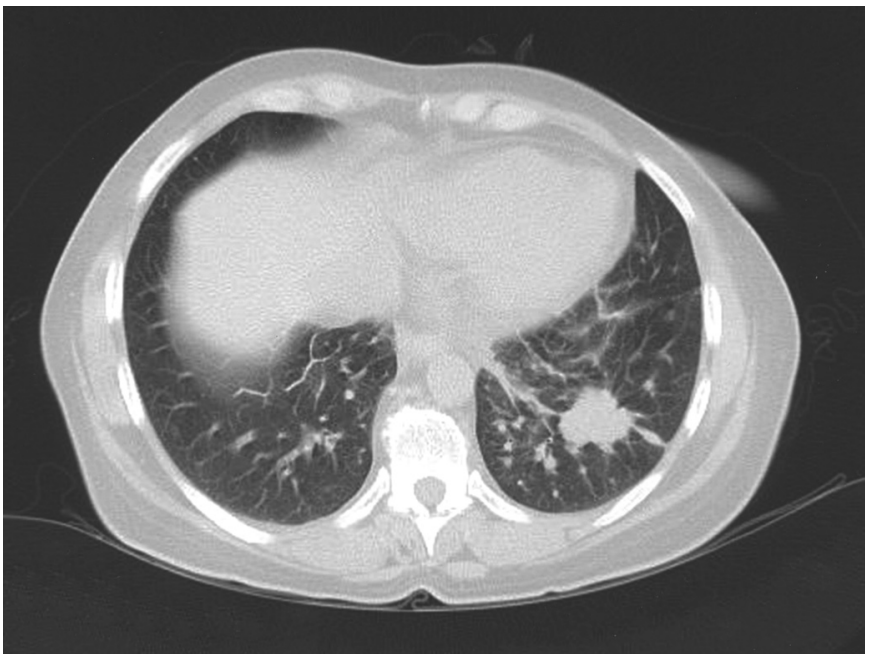

Fig. 1. TAC torácico: Masa de contornos lobulados de 3,5 centrímetros en segmento posterior de lóbulo inferior izquierdo, acompañada de un grueso septo interlobulillar engrosado que contacta con la superficie pleural.

A los 7 días del inicio del tratamiento antibiótico, tras conocer los resutados negativos de los cultivos, se realizó un ecocardiograma de control en el que se observó la aparición de nueva verruga $(5,7$ $\mathrm{mm})$ y disminución de tamaño de la verruga previa $(9,1 \mathrm{~mm})$ Se realizan nuevos hemocultivos para incidir en el diagnostico diferencial de endocarditis con cultivos negativos (HACEK, hongos) y serologías para Legionella, Bartonella, Coxiella, Chlamidias, Mycoplasma...

$\mathrm{Al} 8^{\circ}$ día del inicio del tratamiento, presentó un dolor inespecífico en el hipocondrio izquierdo, realizándose una ecografía abdominal con la sospecha de embolia esplénica no encontrándose patología alguna.

Al $9^{\circ}$ día presentó un cuadro sincopal en el contexto de un accidente isquémico transitorio (debilidad transitoria de extremidad superior izquierda).

Al $11^{\circ}$ día presentó un deterioro clínico importante por cuadro ictal con afectación total de la circulación anterior de la arteria cerebral media izquierda (afasia global, inatención visual y hemiplejía derecha). En el ecocardiograma de control se observó progresión de las lesiones previas y nueva verruga en la cara auricular de la mitral.

Dada la mala evolución clínica y ecocardiográfica se plantea el diagnóstico de ETNB realizándose biopsia de la masa pulmonar siendo está un adenocarcinoma. Se inició tratamiento con heparina intravenosa (i.v.) dada la asociación de ETNB e hipercoagulabilidad, observándose el inicio de una coagulación intravascular diseminada (CID) con aumento del fibrinógeno y del PDF

Los estudios de hipercoagulabilidad, marcadores de crioglobulinemia, antifosfolípido, VIH, VHB, VHC y ANA fueron negativos así como las 12 muestras de hemocultivos y las distintas serologías anteriormente citadas.

La edad, el sexo de la paciente y la presencia de unos marcadores tumorales CA 12,5 y CA 15,3 altos nos llevaron a la búsqueda de un adenocarcinoma primario en mama y ovario sin encontrarse hallazgos.

No se objetivó mejoría clínica y sí empeoramiento radiológico pese a haberse iniciado tratamiento con heparina i.v.

La paciente fue diagnosticada de adenocarcinoma de pulmón en estadio IV con fenómenos embolígenos en el contexto de paraneoplasia. La situación de la paciente con un PS4 contraindicaba cualquier tratamiento de quimioterapia con intención paliativa, siendo únicamente subsidaria de tratamiento sintomático paliativo. En este contexto la paciente es trasladada a Unidad de Paliativos.

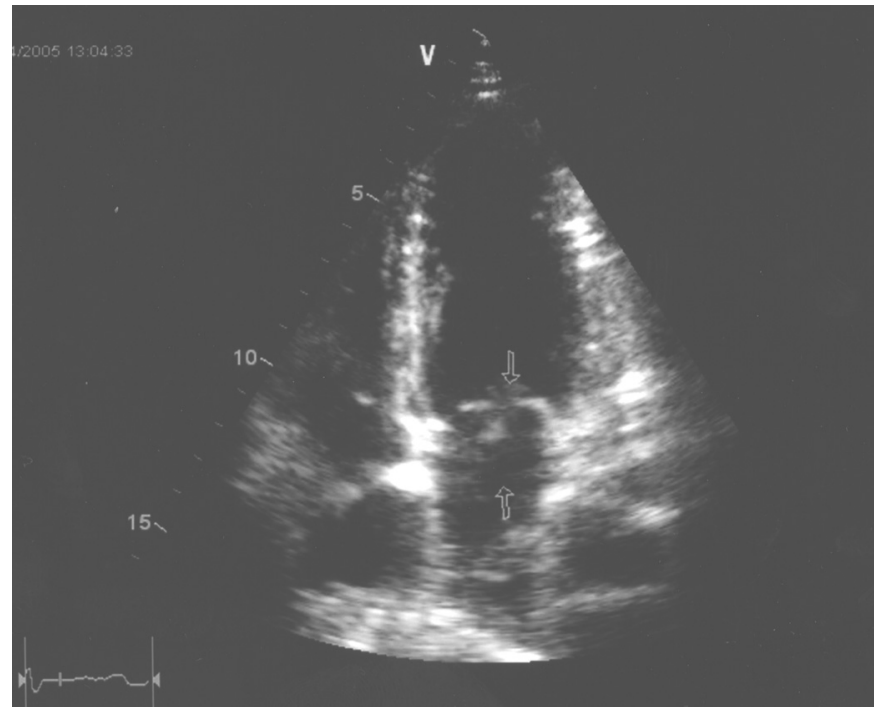

Fig. 2. Ecocardiograma transtorácico: Corte cuatro cámaras en sístole en el que se aprecia una masa adherida a la válvula mitral, tanto en la cara auricular como ventricular (flechas).

\section{DISCUSIÓN}

La ETNB es una entidad relativamente infrecuente caracterizada por la presencia de vegetaciones compuestas por fibrina y plaquetas, no infectadas, con afectación casi exclusiva de la válvula mitral y/o aórtica (2,5-7). Macroscópicamente en el $75 \%$ de los casos las verrugas son menores de 3 milímetros y el $70 \%$ son múltiples (2). Existen discrepancias respecto al grado de afectación valvular, auque esta suele ser ligera o moderada $(1,4,6)$. No existe distribución por sexo y afecta principalmente a pacientes entre la $4^{\mathrm{a}}$ y la $8^{\mathrm{a}}$ décadas de la vida (2).

Aunque la patogénesis de la ETNB no se conoce con exactitud la mayoría de los autores están de acuerdo en la existencia de un daño valvular previo (1); principalmente de origen reumático $(2,4)$, sumado a una alteración de los mecanismos de coagulación que pueden conducir al depósito de plaquetas y agregados de fibrina sobre el endotelio vascular $(1,2)$. También se ha propuesto una base inmunológica y con implicación de los inmunocomplejos.

Es característica su asociación con neoplasias, aunque también se ha descrito en grandes quemados, estados de hipercoagulabilidad, VIH y LES y Síndrome antifosfolípido $(1,4,6,7)$ En un estudio prospectivo se describió en 200 pacientes oncológicos una prevalencia de hasta el 19\% (5). Existen series de autopsias en las que la ETNB se ha asociado con cáncer en aproximadamente el $50 \%$ de los casos (4).

Los tumores que más frecuentemente se asocian con esta patología son los adenocarcinomas (sobre todo de pulmón y páncreas) y los tumores hematológicos $(1,2,4-7)$.

Son características las frecuentes embolizaciones sistémicas; la incidencia descrita varía en un rango del 14\% al $91 \%$ siendo la media aproximadamente el $50 \%(2,3,4,7)$. Los embolismos en pacientes asintomáticos o con sintomatología inespecífica; hematuria, dolor abdominal, torácico o cambios mentales con frecuencia pasan desapercibidos. Las manifesta- 
ciones neurológicas son las más comunes y pueden variar desde déficits focales hasta desorientación generalizada. También se afectan con mucha frecuencia la circulación coronaria, renal, pulmonar y mesentérica $(2,6,7)$.

Se ha objetivado una fuerte correlación entre la CID y la ETNB (2,6,7).

El pronóstico de la ETNB suele ser malo dependiendo de la enfermedad de base.

El tratamiento suele ser el de la enfermedad de base y la heparina iv que dificulta el depósito de plaquetas y fibrina en las válvulas previniendo los efectos tromboembólicos habiéndose asociado su interrupción a muerte3. La terapia con warfarina tiene poca eficacia o no es beneficiosa en prevenir la recurrencia de estos eventos, esto se puede explicar por la ausencia de una etiología vitamina $\mathrm{K}$ dependiente en estas alteraciones de la coagulación (2). Existen discrepancias en cuanto al inicio de la terapia con heparina iv en la prevención del tromboembolismo, bien comenzar si existen complicaciones trombóticas por CID o si se presentan embolias (7) o de inicio tras el diagnóstico de ETNB independientemente de la existencia de CID y/o embolias (3). Dado que no existe consenso en cuanto a cuándo iniciar su administración, optamos por esperar a una sospecha más firme de ETNB, ya que al ser prioritario descartar y tratar empíricamente la endocarditis

\section{Bibliografía}

1 Herrera P, Esteban E, Giménez JV, Pareja A, Moscoso J. Endocarditis trombótica no bacteriana como manifestación inicial de neoplasia pulmonar. An Med Interna (Madrid) 2004; 21: 495-97.

2. López JA, Ross RS, Fishbein MC, Siegel RJ. Nonbacterial thrombotic endocarditis: A review. Am Heart J 1987; 113: 773-84.

3. Salem D, Hartnett D, Levine H, Pauker S, Eckman M, Riff J. Antithrombotic therapy in valvular heart disease. Chest 2001; 119: 207S-219S.

4. Eiken PW, Edwards WD, Tazelaar HD, McBane RD, Zehr KJ. Surgical pathology of nonbacterial thrombotic endocarditis in 30 patients, 19852000. Mayo Clin Proc 2001; 76: 1204-12.

5. Edoute Y, Haim N, Rinkevch D, Brenner B, Reisner SA. Cardiac valvu- infecciosa (EI), en ésta la anticoagulación está contraindicada salvo en pacientes ya previamente anticoagulados por prótesis valvulares (2).

Las lesiones ecocardiográficas de la ETNB son indistinguibles de la EI, por lo que es necesario establecer diagnóstico diferencial con esta entidad (1), éste es especialmente dificultoso en los casos de EI con hemocultivos negativos. Dado que es prioritario descartar EI, se mantuvo el tratamiento antibiótico en espera de ver evolución. El estudio anatomo-patológico, la negatividad de las serologías y los cultivos y la mala evolución clínica y ecocardiográfica condujeron al diagnóstico de ETNB que es esencialmente de presunción $(1,2)$ Este hecho puedo ser la clave para explicar la diferencia entre la práctica clínica y los estudios de autopsia. La presencia de múltiples embolizaciones es más frecuente en la ETNB que en la EI (25-50\%) (8), por lo que ante la presencia de éstas se debe plantear firmemente el diagnóstico de ETNB y más aún si existe enfermedad asociada a ésta (8).

En conclusión, la ETNB se debe tener en cuenta en el diagnóstico diferencial de endocarditis con hemocultivos negativos, sobre todo si cursa con importante afectación embolígena, debiéndose sospechar una neoplasia oculta como causa desencadenante. lar vegetations in cancer patients: A prospective echocardiographic study of 200 patients. Am J Med 1997; 102: 252-57.

6 Reisner SA, Brenner B, Haim N, Edoute, Markiewicz W, Echocardiography in Nonbacterial Thrombotic endocarditis: From autopsy to clinical entity. J Am Soc Echocardiogr 2000; 13: 876-81.

7. Kraft F, Torres A, Giovannoni A, Gidekel L, Endocarditis trombótica no bacteriana como manifestación paraneoplásica de adenocarcinoma pulmonar. Arch Cardiol Mex 2002; 72: 303-5.

8. Horstkotte D, Follath F, Gutschik E, Lengyel M, Oto A, Pavie A, et al. Guía Práctica Clínica sobre prevención, diagnóstico y tratamiento de laendocarditis infecciosa. Rev Esp Cardiol 2004; 57: 952-62. 